\title{
Author's Reply: Management of Enterocutaneous Fistula: Outcomes in 276 Patients
}

\author{
Martha Quinn $^{1} \cdot$ Stuart Falconer $^{1} \cdot$ Ruth $_{\text {McKee }}{ }^{1}$
}

Published online: 23 July 2018

(C) Société Internationale de Chirurgie 2018

We thank Pham and Canada for their interest in our paper [1]. We do have more data about the details of the parenteral nutrition (PN) in our patients but had not analysed this since the focus of the paper was not the content of the parenteral nutrition.

All patients in our study had parenteral nutrition for gastroduodenal or small bowel fistula, though for variable periods of time. This defined entry to the study group. In patients whose fistulas closed with conservative treatment, $\mathrm{PN} /$ nil orally was continued until the fistula closed. If the fistula failed to close by 60 days and sepsis was controlled, oral intake was re-introduced. In patients whose fistula output remained low enough to allow maintenance of fluid and nutritional status without intravenous supplement, PN was discontinued. The results section of the original paper provides details of those who remained on PN either as inpatients or outpatients prior to definitive surgery.

Parenteral nutrition was prescribed by the multidisciplinary team. Dietitians estimated the requirements for protein at $0.2-0.3 \mathrm{gN}(1.25-1.9 \mathrm{~g}$ protein $) / \mathrm{Kg}$ body weight with adjustments for BMI $>30$ and energy using the Henry equation with stress and activity factors added as required (A Pocket Guide to Clinical Nutrition. British Dietetic Association Parenteral and Enteral Nutrition Group. Eds Todorovic and Micklewright). Any electrolyte abnormalities were corrected by adjusting the PN volume and electrolyte content. Our institution uses 6 commercially produced "standard" PN bags, adjusted by adding volume and extra electrolytes if needed. Approximately one in ten patients required bespoke parenteral nutrition, often because of high losses from their fistula. No specific additional nutrients such as glutamine, arginine or selenium were used. A variety of fat sources were used over the years, initially soya but latterly olive oil based. If PN was needed for longer than 1 month, care was taken to reduce the amount of fat to less than $1 \mathrm{~g} / \mathrm{Kg} / \mathrm{day}$, usually by using only 1-2 PN bags with fat per week. If the liver function tests became abnormal, excess energy intake, sepsis and other causes were excluded and feed containing SMOF lipid was used (Fresenius Kabi).

Some patients transferred from other hospitals had somatostatin or its analogues before transfer, but no patient was continued on this long-term following transfer.

\section{Reference}

1. Quinn M, Falconer S, McKee RF (2017) Management of enterocutaneous fistula: outcomes in 276 patients. World J Surg 41:2502-2511. https://doi.org/10.1007/s00268-017-4063-y
Martha Quinn

martha.quinn@doctors.org.uk

Glasgow Royal Infirmary, Glasgow, Scotland, UK 